\title{
Identification of a novel autoantibody against self-vimentin specific in secondary Sjögren's syndrome
}

\author{
Yu-Hui Li ${ }^{1 \dagger}$, Ya-Ping Gao ${ }^{2 \dagger}$, Jie Dong ${ }^{2 \dagger}$, Lian-Jie Shi ${ }^{1}$, Xiao-Lin Sun ${ }^{1}, \mathrm{Ru} \mathrm{Li}^{1}$, Xue-Wu Zhang ${ }^{1}$, Yu Liu', Li Long ${ }^{1}$, \\ Jing He ${ }^{1}$, Qun-Jie Zhong ${ }^{3}$, Eric Morand ${ }^{4 *}$, Guang Yang ${ }^{2^{*}}$ and Zhan-Guo Li $i^{* *}$
}

\begin{abstract}
Background: Sjögren's syndrome (SS) is a primary autoimmune disease (pSS) or secondarily associated with other autoimmune diseases (sSS). The mechanisms underlying immune dysregulation in this syndrome remain unknown, and clinically it is difficult to diagnose owing to a lack of specific biomarkers.

Methods: We extracted immunoglobulins (Igs) from the sera of patients with sSS associated with rheumatoid arthritis (RA) and used them to screen a phage display library of peptides with random sequences.

Results: Our results show that an sSS-specific peptide, designated 3S-P, was recognized by sera of $68.2 \%$ (60 of 88 ) patients with sSS, $66.2 \%$ of patients with RA-sSS, and 76.5\% of patients with systemic lupus erythematosus (SLE)-sSS. The anti-3S-P antibody was scarcely found in patients with pSS (1.8\%), RA (1.3\%), SLE (4.2\%), ankylosing spondylitis (0\%), and gout (3.3\%), as well as in healthy donors (2\%). The 3S-P-binding lgs (antibodies) were used to identify antigens from salivary glands and synovial tissues from patients with sSS. A putative target autoantigen expressed in the synovium and salivary gland recognized by anti-3S-P antibody was identified as self-vimentin.
\end{abstract}

Conclusions: This novel autoantibody is highly specific in the diagnosis of sSS, and the underlying molecular mechanism of the disease might be epitope spreading involved with vimentin.

Keyword: Sjögren's syndrome, Biomarker, Autoantigen, Vimentin

\section{Background}

Sjögren's syndrome (SS) is a systemic autoimmune disease characterized by marked reduction of exocrine glandular secretions, and it progresses to lymphocytic infiltration and destruction of exocrine glands [1-3]. In addition to arising as a primary disease (primary Sjögren's syndrome [pSS]), pSS occurs in association with other autoimmune diseases (secondary Sjögren's syndrome [sSS]), particularly rheumatoid arthritis (RA) and systemic lupus erythematosus (SLE) [4-7]. The

\footnotetext{
*Correspondence: eric.morand@monash.edu; yangg62033@163.com; uhuili84@163.com; li99@bjmu.edu.cn

${ }^{\dagger}$ Equal contributors

${ }^{4}$ Center for Inflammatory Diseases, Southern Clinical School, Monash University, Melbourne, Australia

${ }^{2}$ Beijing Institute of Basic Medical Sciences, Beijing, China

'Department of Rheumatology \& Immunology, Peking University People's

Hospital, 11 Xizhimen South Street, Beijing 100044, China

Full list of author information is available at the end of the article
}

impact of sSS on RA is illustrated by a twofold increased risk of non-Hodgkin's lymphoma compared with patients with RA without sSS, and there is a tendency toward increased mortality in patients with RA with sSS compared with those without sSS [8-10]. Patients with SLE and SS more commonly had renal, peripheral vascular, and musculoskeletal damage than those with SLE without SS [11].

Evidence indicates that the clinical and immunological features of patients with sSS differ from those of patients with pSS [12]. Antinuclear antibody, anti-SSA, and antiSSB have been applied to the diagnosis of SS, but none of these autoantibodies provides sufficient specificity and sensitivity [13-15]. The molecular mechanism of sSS is unknown, and the lack of specific biomarkers constrains efforts to establish the clinical diagnosis of and intervention for the disease. Therefore, the aim of the present 
study was to identify potential biomarkers and molecules that are specifically associated with sSS. We employed a strategy successfully applied to collagen-induced arthritis, autoimmune pancreatitis, and other autoimmune diseases using a library of peptides with random sequences [16-19]. We report the identification of a novel autoantibody that was specifically associated with sSS and recognized vimentin as an autoantigen of the disease.

\section{Methods}

\section{Participants}

We obtained serum samples from patients and healthy control subjects (HCs) between January 2004 and June 2011 at the People's Hospital of Peking University. Patients diagnosed with sSS fulfilled the 2002 classification criteria for sSS [20]. Immunological data collected from medical files included the presence of antinuclear antibodies, anti-SSA and anti-SSB antibodies, rheumatoid factor, as well as other antibodies such as anti-double-stranded DNA. Blood samples were obtained after subjects provided written informed consent, and the local ethics committee approved the study. All serum samples were stored at $-20{ }^{\circ} \mathrm{C}$. For the serological antigen selection procedure, immunoglobulins (Igs) were pooled from serum samples of ten patients with sSS with RA (all patients fulfilled the 2010 classification criteria for RA) [21], ten patients with RA without SS, and ten HCs. For further validation of the identified markers, plasma samples were obtained from 88 patients with sSS (71 with RA and 17 with SLE), 99 HCs, 55 patients with pSS, 79 patients without sSS but with RA, 24 patients with SLE, 21 patients with ankylosing spondylitis, and 30 patients with gout. The characteristics of patients with sSS and HCs included in the study are summarized in Table 1 and Additional file 1: Tables S1-S3.

Table 1 Clinical characteristics of patients

\begin{tabular}{llll}
\hline Diagnosis & No. of subjects & Mean age, years (range) & $\begin{array}{l}\text { Female/male } \\
\text { sex (no.) }\end{array}$ \\
\hline RA-sSS & 71 & $54.2(27-84)$ & $64 / 7$ \\
SLE-sSS & 17 & $47.3(23-70)$ & $15 / 2$ \\
RA & 79 & $55.9(26-77)$ & $73 / 6$ \\
pSS & 55 & $55.3(21-79)$ & $52 / 3$ \\
SLE & 24 & $36.3(20-75)$ & $21 / 3$ \\
AS & 21 & $41.0(18-59)$ & $12 / 9$ \\
Gout & 30 & $54.4(35-80)$ & $27 / 3$ \\
HC & 99 & $43.4(22-59)$ & $89 / 10$ \\
\hline
\end{tabular}

Abbreviations: AS Ankylosing spondylitis, HC Healthy control subject, $p S S$ Primary Sjögren's syndrome, RA Rheumatoid arthritis, SLE Systemic lupus erythematosus, SS Sjögren's syndrome, sSS Secondary Sjögren's syndrome

\section{Peptide library}

A random dodecamer peptide library that expresses peptides on a phage virion was purchased from New England Biolabs (Ipswich, MA, USA). The peptide library was screened against three pooled IgG fractions. Each fraction was purified from the pooled sera of ten patients with RA-sSS. To enrich for specific binding phage clones (putatively disease-related), IgGs from ten patients with RA and ten HCs were employed to subtract nonspecific binding clones. Aliquots of $2 \times 10^{11}$ plaque-forming units in $0.05 \%$ PBS with Tween 20 (PBST) were added to IgG-coated wells of a polyvinyl chloride microtiter plate and incubated for 60 minutes at room temperature. The wells were washed ten times with $0.1 \%$ PBST, and bound phages were eluted with acidic elution buffer $(20 \mathrm{mmol} / \mathrm{L}$ Gly-HCl, $\mathrm{pH} 2.2)$. Low$\mathrm{pH}$ eluate was immediately neutralized with $1 \mathrm{~mol} / \mathrm{L}$ Tris- $\mathrm{HCl}, \mathrm{pH}$ 9.1. Eluates were amplified by infecting Escherichia coli ER2738 host cells (New England Biolabs). After $4.5 \mathrm{~h}$ of vigorous shaking at $37^{\circ} \mathrm{C}$, bacteria were removed by centrifugation. Phage particles were purified by two consecutive precipitations with polyethylene glycol (PEG)/ $\mathrm{NaCl}$ (20\% PEG-8000, $2.5 \mathrm{~mol} / \mathrm{L}$ $\mathrm{NaCl}$ ) and then resuspended in PBS. These amplified eluates were titered to determine phage concentration and then used as the input phage for the next selection round. Finally, unamplified eluate from the third round of biopanning was used to infect plated bacterial host cells. Single phage clones were assayed by enzymelinked immunosorbent assay (ELISA). DNA was extracted from positive clones and sequenced.

\section{Analysis of antibody binding}

Antibody reactivity against peptides was measured using a solid-phase ELISA. Synthetic purified peptides were coated overnight at $4{ }^{\circ} \mathrm{C}$ at $2 \mu \mathrm{g} /$ well in $0.1 \mathrm{M}$ sodium hydrogen carbonate buffer, $\mathrm{pH}$ 9.6. Unbound antibodies were discarded, and wells were blocked with $5 \%$ bovine serum albumin (BSA) for $1 \mathrm{~h}$ at $37{ }^{\circ} \mathrm{C}$. Serum samples diluted 1:25 in 1\% BSA were added to the wells and incubated for $1 \mathrm{~h}$. After a washing step with PBS containing $0.5 \%$ ( $\mathrm{vol} / \mathrm{vol})$ Tween 20 , antibody binding was detected by incubation with a goat antihuman IgG horseradish peroxidase-conjugated antibody, followed by color development using 3,3',5,5' -tetramethylbenzidine as a substrate. The reaction was stopped by adding $1 \mathrm{~mol} / \mathrm{L} \mathrm{H}_{2} \mathrm{SO}_{4}$, and the color intensity was measured at $450 \mathrm{~nm}$. Absorbance values greater than 3 SDs above the mean for each serum dilution of the control group were considered positive.

\section{Preparation of polyclonal anti-3S-P antibodies}

The peptide YSLHNAGPWSLHQ, designated 3S-P (secondary Sjögren's syndrome-related peptide), was 
manually synthesized using a standard method [19] for solid-phase peptide synthesis. Polyclonal antibodies against the 3S-P were generated in New Zealand white rabbits using standard techniques (R-anti-3S-P) [22]. Ranti-3S-P antibodies were purified using an immunoaffinity column, which was prepared by conjugating the peptide to SulfoLink Coupling Resin (Pierce Biotechnology/Thermo Fisher Scientific, Rockford, IL, USA) according to the manufacturer's instructions [23].

\section{Human synovial tissue, salivary gland biopsies, and cells}

Synovial tissue specimens and fluid were obtained from patients with RA-sSS during joint replacement surgery at People's Hospital Peking University in China. Salivary gland specimens were obtained from patients with sSS during salivary gland biopsies. All the methods were carried out in accordance with the guidelines and regulations issued by the Ethics Committee of People's Hospital Peking University. Human primary fibroblastlike synoviocyte (FLS) cultures were established as previously described with some modifications [24]. Briefly, tissue pieces were minced, treated with $1 \mathrm{mg} / \mathrm{ml}$ collagenase for $1 \mathrm{~h}$ at $37^{\circ} \mathrm{C}$, and passed through a cell strainer. The cell suspension was incubated at $37{ }^{\circ} \mathrm{C}$ in complete DMEM in an atmosphere containing $5 \% \mathrm{CO}_{2}$. Cells were harvested at passages 3 through 6 .

\section{Immunohistochemistry}

Sections of the synovial or salivary gland were mounted on glass slides. Immunohistochemical analysis was performed as previously described [25]. R-anti-3S-P and anti-keyhole limpet hemocyanin (anti-KLH) antibodies were used as primary antibodies $(25 \mu \mathrm{g} / \mathrm{ml}$ each). The sections were subsequently stained with horseradish peroxidase-conjugated antirabbit antibody (Abcam, Cambridge, UK). Detection was accomplished using diaminobenzidine, and sections were counterstained with hematoxylin.

\section{Immunofluorescence and confocal microscopy}

FLSs obtained from patients with RA were immobilized, fixed, and permeabilized as previously described [21]. Cells were incubated with $1 \%$ BSA for 30 minutes before incubation. The fixed cells were incubated with the purified antibodies $(25 \mu \mathrm{g} / \mathrm{ml}$ each) for 60 minutes. After a washing step, the cells were incubated with fluorescein isothiocyanate-conjugated goat antihuman IgG diluted 1:200, and nuclei were stained with 4',6-diamidino-2phenylindole.

\section{Western blot analysis}

Proteins extracted from FLSs were electrophoresed and transferred onto a Hybond ECL nitrocellulose membrane (GE Healthcare Life Sciences, Marlborough, MA,
USA). The membranes were incubated with affinitypurified polyclonal R-anti-3S-P antibodies $(5 \mu \mathrm{g} / \mathrm{ml})$ and then with horseradish peroxidase-conjugated goat antirabbit IgG.

\section{Two-dimensional gel electrophoresis}

Proteins obtained from FLSs were separated by twodimensional gel electrophoresis. Protein samples were loaded onto immobilized $\mathrm{pH}$ gradient gel strips (GE Healthcare Life Sciences). After rehydration for $14 \mathrm{~h}$, isoelectric focusing (IEF) was carried out for $1 \mathrm{~h}$ at $200 \mathrm{~V}, 1 \mathrm{~h}$ at $500 \mathrm{~V}$, and $1 \mathrm{~h}$ at $1000 \mathrm{~V}$ continuously, then a gradient was applied from 1000 to 8000 for $1 \mathrm{~h}$ and finally at $8000 \mathrm{~V}$ for $8 \mathrm{~h}$ to reach a total of $72 \mathrm{KVh}$ at $20{ }^{\circ} \mathrm{C}$. Following IEF separation, gel strips were incubated in equilibration buffer $(50 \mathrm{mM}$ Tris- $\mathrm{HCl}, \mathrm{pH} 8.8$, 6 M urea, $30 \%$ glycerol, $2 \%$ sodium dodecyl sulfate [SDS]) with $10 \mathrm{mg} / \mathrm{ml}$ dithiothreitol for 15 minutes, followed by equilibration buffer with $25 \mathrm{mg} / \mathrm{ml}$ iodoacetamide for 15 minutes. Then strips were loaded onto 12.5\% SDS-PAGE gels and electrophoresed for $20 \mathrm{mi}-$ nutes at a constant current of $10 \mathrm{~mA}$ and then at $30 \mathrm{~mA}$ per gel until the bromophenol blue reached the bottom of the gels. Subsequently, the two-dimensional gel was silver-stained and scanned. The digital images were analyzed using the GS-800 image scanner (Bio-Rad Laboratories, Hercules, CA, USA) at 300-dpi resolution. Spot detection, quantification, and analyses of twodimensional protein patterns were done using PDQuest 2-D Analysis software version 7.2 (Bio-Rad Laboratories). Then the report of quantitative differences between two gel images was generated. The $t$ test was performed to compare the relative volume of spots in gels. Significant spots were selected for protein identification.

\section{MS analysis and data interpretation}

The bands of interest were excised from the gels and digested with trypsin. The trypsin-digested samples were initially transferred with an aqueous $0.1 \%$ formic acid solution to the precolumn at a flow rate of $5 \mu \mathrm{l} /$ minute for 4 minutes. Mobile phase A was water with $0.1 \%$ formic acid, and mobile phase B was $0.1 \%$ formic acid in acetonitrile. The peptides were separated with a linear gradient of $10-40 \%$ mobile phase B over 60 minutes at $200 \mathrm{nl} /$ minute, followed by 10 minutes at $85 \%$ mobile phase B. The column was re-equilibrated at initial conditions for 10 minutes. The column temperature was maintained at $35{ }^{\circ} \mathrm{C}$. The lock mass was delivered from the auxiliary pump of the nanoACQUITY pump (Waters, Milford, MA, USA) with a constant flow rate of $400 \mathrm{nl} /$ minute at a concentration of $100 \mathrm{fmol} / \mu \mathrm{l}$ [Glu1]fibrinopeptide B. Analysis of trypsin peptides was performed using a SYNAPT high-definition mass spectrometer (Waters). For all measurements, the mass 
spectrometer was operated in V-mode with a typical resolving power of at least 10,000 FWHM. The time-offlight (TOF) analyzer of the mass spectrometer was calibrated with the MS/MS fragmentations of [Glu1]-fibrinopeptide B from 50 to 1600 mass/charge ratio. The reference sprayer was sampled with a frequency of 30 seconds. Accurate LC-MS and MS/MS data were collected in high definition data-directed analysis mode. LC-MS/MS data were processed using ProteinLynx Global SERVER version 2.3 (PLGS 2.3; Waters), and the resulting peak lists were subjected to a search against the National Center for Biotechnology information (NCBI) protein database of with the Mascot search engine.

\section{Immunoprecipitation}

The mouse antivimentin antibody was incubated with the FLS protein extract $(400 \mu \mathrm{l})$ for $3 \mathrm{~h}$ at $4{ }^{\circ} \mathrm{C}$. Next, protein G-conjugated magnetic beads $(100 \mu \mathrm{l})$ were added and incubated for $1 \mathrm{~h}$ at $4{ }^{\circ} \mathrm{C}$, and the beads were collected and washed as instructed by the manufacturer. Laemmli sample buffer was added next, and the mixture was heated for 5 minutes at $95{ }^{\circ} \mathrm{C}$. The supernatants were collected after centrifugation and subjected to SDS-PAGE and Western blot analysis. To detect the 3S$\mathrm{P}$ antigen, the anti-3S-P serum was diluted to $1: 800$, and peroxidase-conjugated goat antirabbit IgG was used as the secondary antibody. An antivimentin antibody was used at 1:1000 dilution.

\section{Statistical analyses}

We evaluated the sensitivity and specificity of the tests using the ROC curve and estimated the AUC at 95\% CIs. Statistical analysis was performed using SPSS software version 16 (SPSS, Chicago, IL, USA).

\section{Results}

Identification of a peptide specifically recognized by sera from patients with sSS

We screened a phage display library of random peptides using pooled protein A affinity-purified and dialyzed IgGs from ten patients with RA-sSS for specific binding to peptides. Phage clones with the sequence YSLHNAGPWSLQ specifically bound to the IgGs of patients with RA-sSS, which was confirmed by three rounds of screening with the same pooled IgGs. The dodecamer peptide was designated as 3S-P. Further investigation revealed that this peptide was recognized by sera of $68.2 \%$ (60 of 88 ) patients with sSS (66.2\% of patients with RAsSS and $76.5 \%$ of patients with SLE-sSS) (Fig. 1a). In contrast, anti-3S-P was barely detectable in patients with pSS, other those with rheumatic diseases, and HCs. The prevalence rates were $1.8 \%$ ( 1 of 55 ) in pSS, 1.3\% (1 of 79 ) in RA, 4.2\% (1 of 24) in SLE, 3.3\% (1 of 30) in gout,

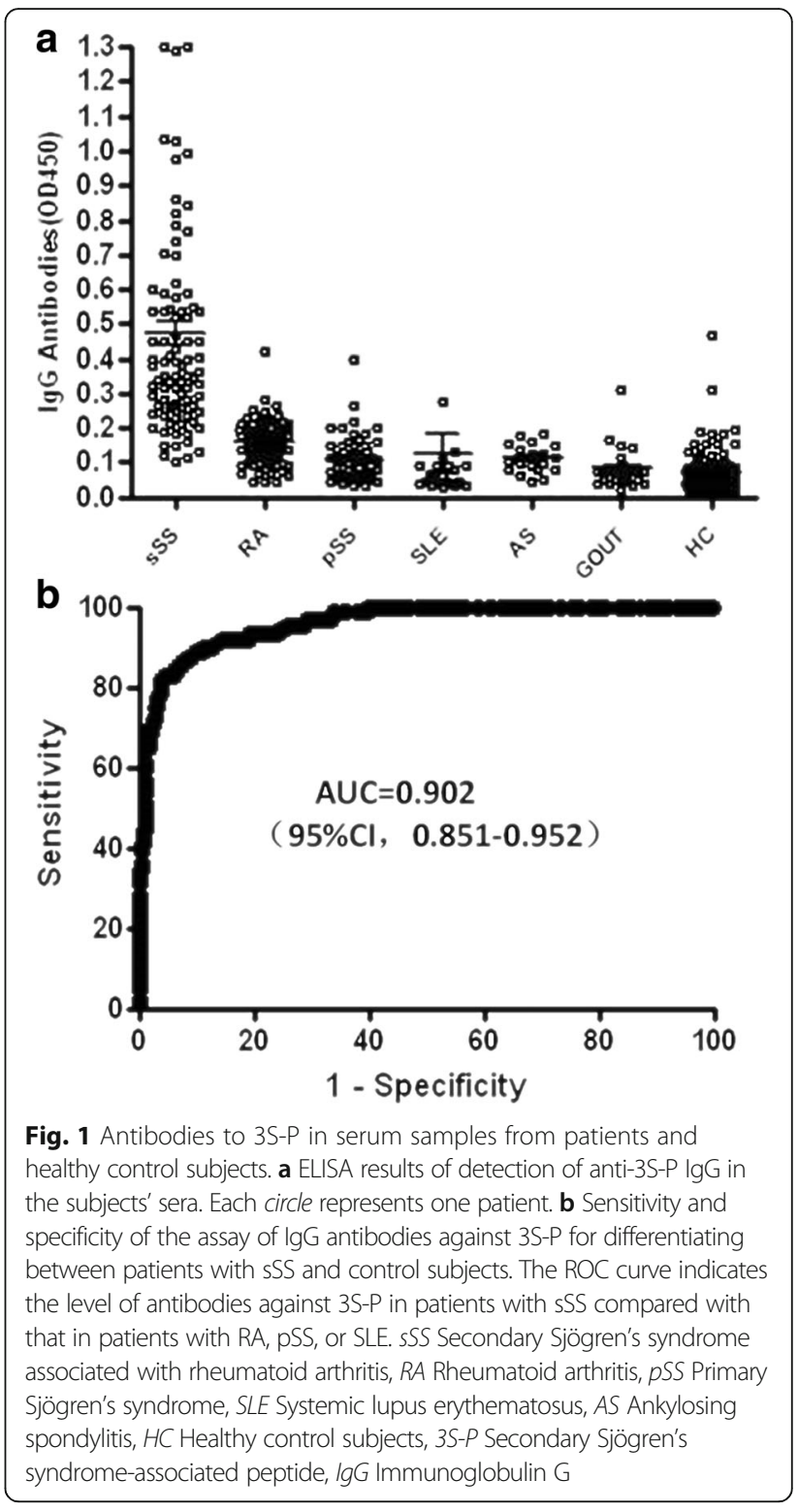

and 2\% (2 of 99) in HCs, respectively. We did not detect reactivity of 3S-P with sera from 21 patients with ankylosing spondylitis ( $0 \%$ [0 of 21]). The sensitivity and specificity of detection of anti-3S-P in sera of patients with sSS (RA-sSS and SLE-sSS), with a cutoff absorbance value of 0.29 at $450 \mathrm{~nm}$, were $68.2 \%$ and $98.1 \%$, respectively. The AUC of the ROC was 0.902 (95\% CI 0.851-0.952; $P<0.001$ ) (Fig. 1b).

\section{Autoantigen is expressed in synovial membrane and salivary gland}

To identify the target antigen of the anti-3S-P antibody in patients with sSS, we prepared an R-anti-3S-P antibody and performed immunohistochemical analysis of synovial and salivary gland tissues from patients with RA-sSS (Additional file 1: Figure S1). We found that the 
synovial lining layer and ductal cells of the salivary glands from all patients were strongly stained by the Ranti-3S-P antibody (Fig. 2a) and that the target recognized by R-anti-3S-P was present in the cytoplasm of cultured FLSs (Fig. 2b).

\section{Vimentin is autoantigen in sSS}

Total proteins extracted from FLSs were analyzed using two-dimensional gel electrophoresis. Compared with control anti-KLH, two spots were recognized by R-anti3S-P in Western blot analysis (Fig. 3a). The proteins in the two spots were identified as vimentin, heat shock protein 60 (HSP60), and caldesmon isoform 2 using MS analysis. Vimentin and HSP60 were identified from the spots at $55 \mathrm{kDa}$, and caldesmon isoform 2 was identified from the spot at $72 \mathrm{kDa}$ (Fig. 3b).

To further confirm the results derived by MS, we performed immunoprecipitation to pull down target

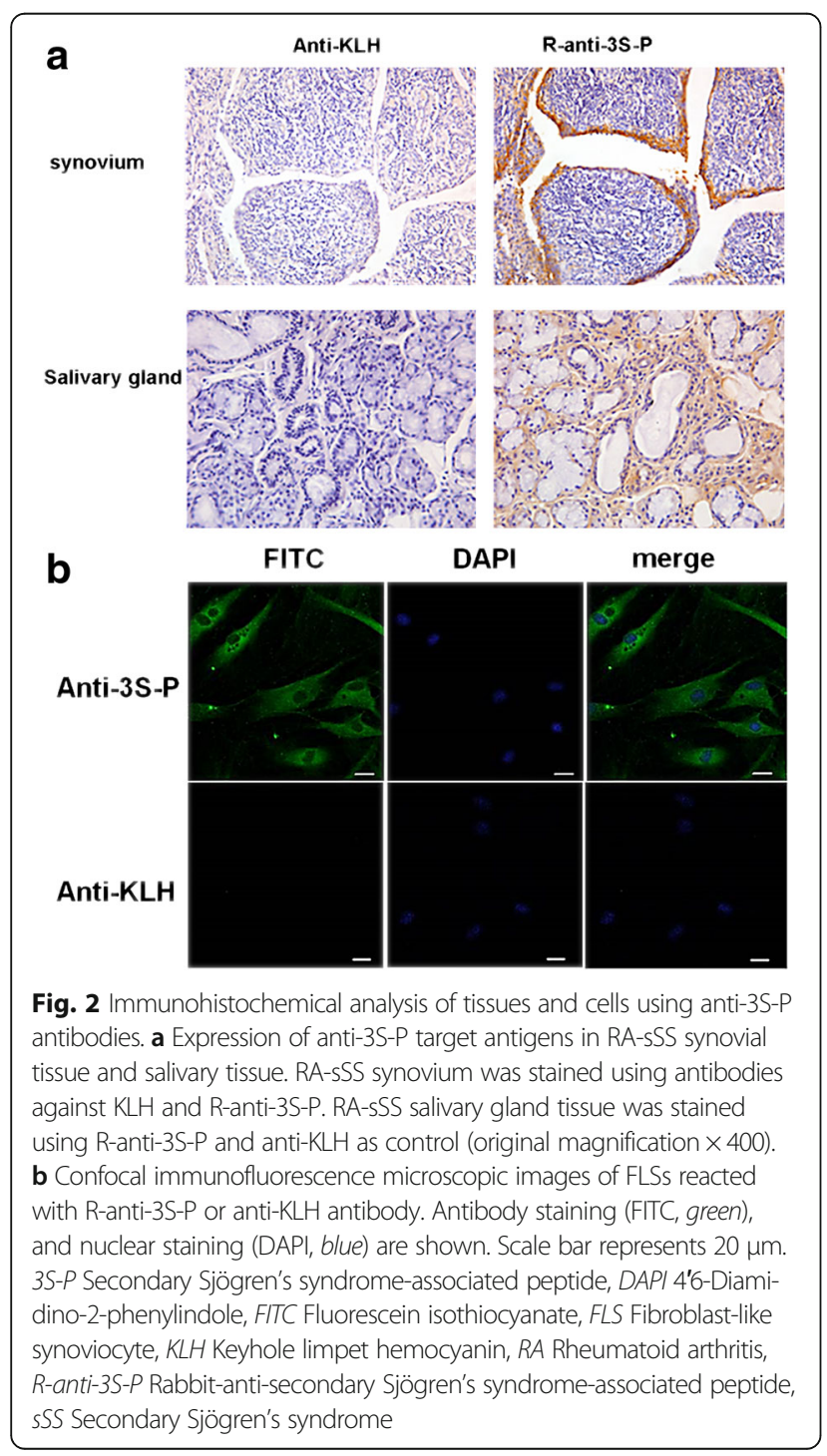

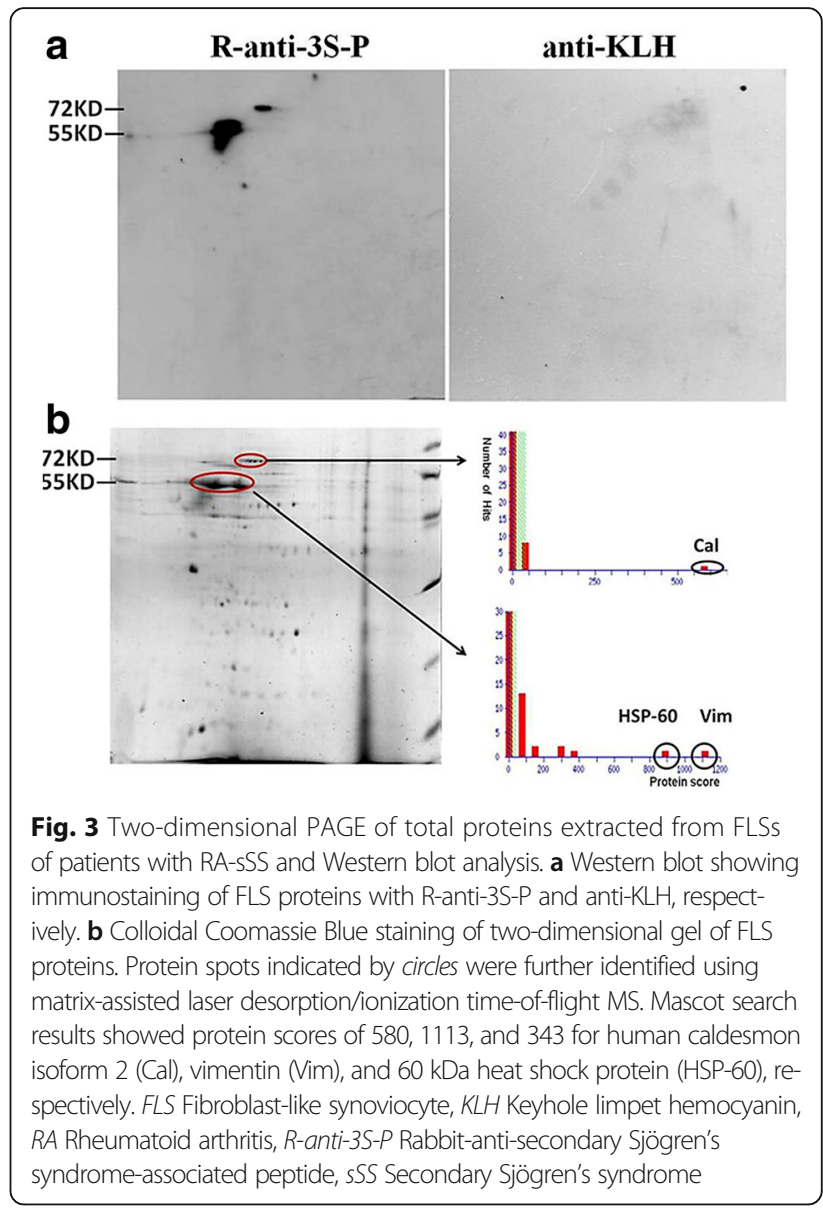

proteins using antibodies against vimentin, HSP60, and caldesmon isoform 2 . Western blot analysis revealed that each protein was detected by the cognate respective antibody in extracts of FLSs (Fig. 4). However, R-anti3S-P recognized the protein precipitated by the antivimentin antibody, not by anti-KLH (Fig. 5a).

Using BLASRP software from the BLAST network service of the NCBI, we found that the sequence of 3S-P is highly similar to that of amino acid residues 282-293 of vimentin (Fig. 6). Moreover, the R-anti-3S-P antibodies detected recombinant human vimentin in ELISA (Fig. 5b) and Western blotting (Fig. 5c) experiments.

\section{Discussion}

In clinical practice, there is no specific serologic marker for sSS, and the immunopathology of this condition is poorly understood. Diagnosis relies on salivary gland biopsy, which is invasive, requires evaluation by an expert histopathologist, and may have adverse sequelae [26]. We report the detection of an antibody against 3S-P in 60 of 88 of patients with sSS in the present study. This assay was highly sensitive and specific for distinguishing sSS from pSS. Furthermore, the profile of reactivity of anti-3S-P differs from those reported for anti-SSA and 


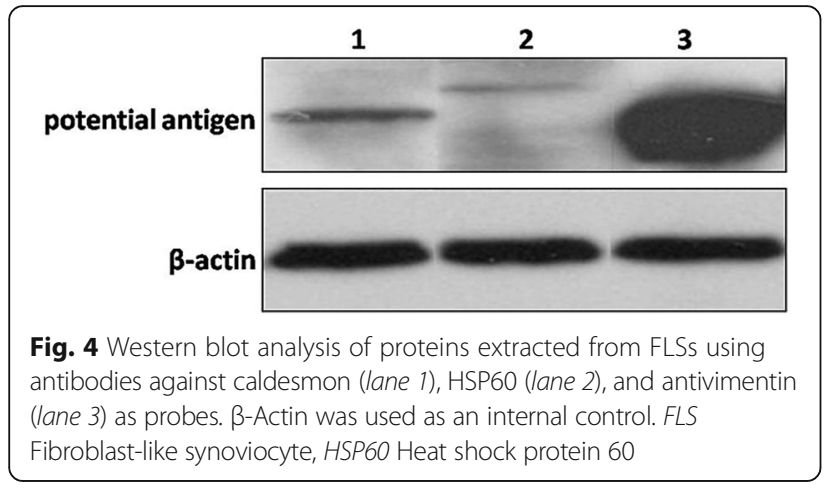

anti-SSB $[14,15]$, which suggests that the antigen recognized by anti-3S-P differs from those recognized by antiSSA and anti-SSB. Taken together, these results indicate that the immunopathogenesis of sSS differs from that of pSS.

In the present study, we determined that vimentin is an autoantigen recognized by anti-3S-P. In humans, vimentin is expressed by a wide variety of mesenchymal

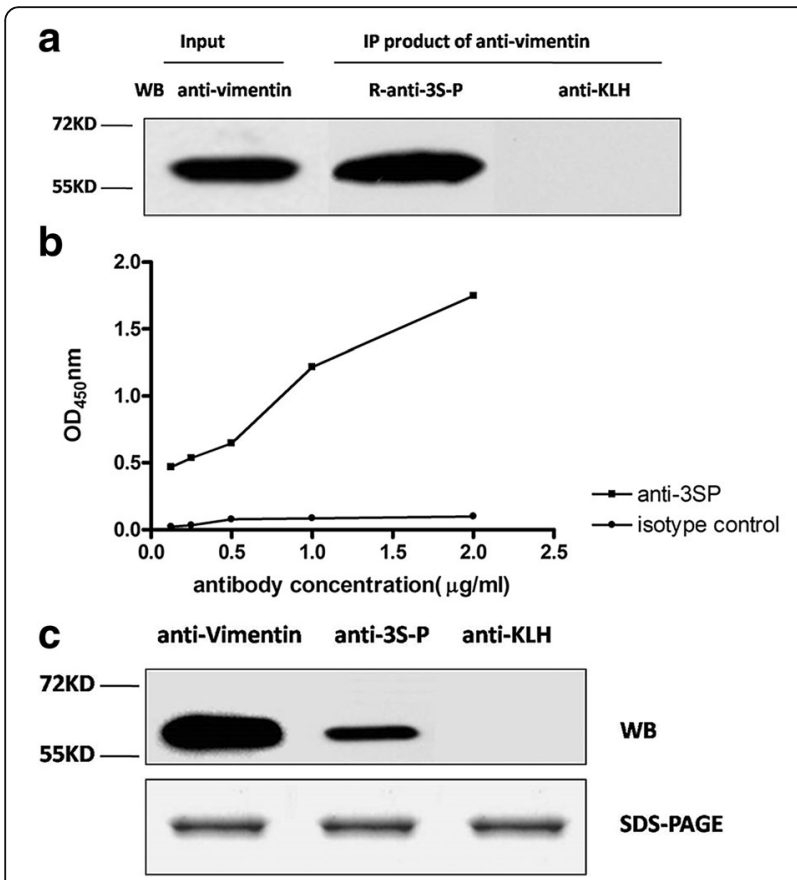

Fig. 5 Identification of vimentin as the target autoantigen of anti-3S-P autoantibodies. a Autoantigens of anti-3S-P and vimentin are present in immunoprecipitates (IP) obtained by using antivimentin antibody from lysates of FLSs, whereas no band was seen in negative controls. b ELISA data for the detection of recombinant human vimentin using the R-anti-3S-P antibody diluted 1:50 to 1:800. The anti-KLH antibody was used as an isotype control and was diluted 1:50 to 1:800. c Western blot (WB) of recombinant human vimentin probed with antivimentin, $\mathrm{R}$ anti-3S-P, and anti-KLH antibodies. ELISA Enzyme-linked immunosorbent assay, FLS Fibroblast-like synoviocyte, KLH Keyhole limpet hemocyanin, $R$ anti-3S-P Rabbit-anti-secondary Sjögren's syndrome-associated peptide, SDS Sodium dodecyl sulfate

\section{Sequence homology between 3S-P and vimentin \\ 3S-P peptide $e_{1-12}$ YSLHNAGPWSLQ \\ Vimentin (282-293)

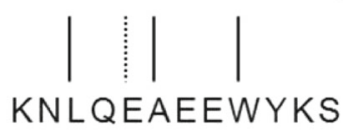

Fig. 6 Peptide sequence homologies. Identity is indicated by solid lines, and a conservative substitution is indicated by the dotted line

cell types, such as fibroblasts and endothelial cells, and is easily detected in the synovium [27, 28]. Antibodies against citrullinated vimentin are prominent in the development of RA [29-32]. Our results show that the antibody present in the majority of patients with sSS tested, which we designated as anti-3S-P, reacted with noncitrullinated recombinant human vimentin. This indicates that the production of anti-3S-P antibodies in patients with sSS may result from epitope spreading, which occurs in several models of autoimmunity [33-36]. There is no evidence, to our knowledge, that antivimentin antibodies are present in patients with SLE. Therefore, the occurrence and clinical correlates of anti-3S-P antibodies in patients with SLE should be investigated further.

\section{Conclusions}

In the present study, we identified an antibody that is highly specific and sensitive for sSS. Further studies are required to determine whether this peptide antibody is useful for clinical diagnosis of sSS and involved in disease pathogenesis. We have demonstrated a novel autoantibody that is highly specific in the diagnosis of sSS and that vimentin is an autoantigen recognized by anti-3S-P. The underlying molecular mechanism of the disease might be epitope spreading involved with vimentin.

\section{Additional file}

Additional file 1: Table S1. Clinical and serological data comparing RA with and without sSS. Table S2. Clinical and serological data comparing sSS and pSS. Table S. Characteristics of the patients used for library screening. Figure S1. Immunohistochemical analysis of tissues and cells using anti-3S-P antibodies. (DOCX 237 kb)

\section{Abbreviations}

3S-P: Secondary Sjögren's syndrome-associated peptide; AS: Ankylosing spondylitis; BSA: Bovine serum albumin; DAPI: 4',6-Diamidino-2-phenylindole; ELISA: Enzyme-linked immunosorbent assay; FITC: Fluorescein isothiocyanate; FLS: Fibroblast-like synoviocyte; HC: Healthy control subject; HSP60: Heat shock protein 60; IEF: Isoelectric focusing; Igs: Immunoglobulins; KLH: Keyhole limpet hemocyanin; NCBI: National Center for Biotechnology information; OD: Optical density; PBST: PBS with Tween 20; PEG: Polyethylene glycol; pSS: Primary Sjögren's syndrome; RA: Rheumatoid arthritis; R-anti-3S-P: Rabbit-anti-secondary Sjögren's syndrome-associated peptide; SDS: Sodium dodecyl sulfate; SLE: Systemic lupus erythematosus; SS: Sjögren's syndrome; sSS: Secondary Sjögren's syndrome; TOF: Time of flight 


\section{Acknowledgements}

The authors thank all the patients who participated in this study. Furthermore, the authors acknowledge C. Liu, Dr. Z. Pei, and Dr. J. X. Zhu for their contributions to clinical data collection.

\section{Funding}

This work was supported by the National Natural Science Foundation of China (81671602 and 31530020) and the Beijing Nova Program (Z171100001117025)

\section{Availability of data and materials}

The dataset generated during the present study is available from the corresponding author on reasonable request.

\section{Authors' contributions}

YHL and JD performed the majority of the experiments and drafted the manuscript. YPG screened the peptide library. XLS, RL, XWZ, YL, and QJZ obtained patients' synovial tissues and clinical data at Peking University People's Hospital. LL and JH carried out the cell cultures. LJS contributed to data analysis. EM interpreted data and wrote the paper. ZGL and GY designed the study. All authors read and approved the final manuscript.

\section{Ethics approval and consent to participate}

All the procedures involving specimens obtained from human subjects were performed under protocols approved by the Human Research Protective Committee of People's Hospital Peking University, and all the methods were carried out in accordance with the guidelines and regulations of the Ethics Committee of People's Hospital Peking University. Informed consent was also provided by all subjects before the study protocol was initiated.

\section{Consent for publication}

\section{Not applicable.}

\section{Competing interests}

The authors declare that they have no competing interests.

\section{Publisher's Note}

Springer Nature remains neutral with regard to jurisdictional claims in published maps and institutional affiliations.

\section{Author details}

'Department of Rheumatology \& Immunology, Peking University People's Hospital, 11 Xizhimen South Street, Beijing 100044, China. ${ }^{2}$ Beijing Institute of Basic Medical Sciences, Beijing, China. ${ }^{3}$ Arthritis Clinic and Research Center, Peking University People's Hospital, Beijing, China. ${ }^{4}$ Center for Inflammatory Diseases, Southern Clinical School, Monash University, Melbourne, Australia.

Received: 16 July 2017 Accepted: 28 December 2017

Published online: 12 February 2018

\section{References}

1. Fox RI. Sjögren's syndrome. Lancet. 2005;366(9482):321-31.

2. Mariette $X$, Gottenberg JE. Pathogenesis of Sjögren's syndrome and therapeutic consequences. Curr Opin Rheumatol. 2010;22(5):471-7.

3. Tzioufas AG, Kapsogeorgou EK, Moutsopoulos HM. Pathogenesis of Sjögren's syndrome: what we know and what we should learn. J Autoimmun. 2012;39(1-2):4-8.

4. Uhlig T, Kvien TC, Jensen JL, Axéll T. Sicca symptoms, saliva and tear production, and disease variables in 636 patients with rheumatoid arthritis. Ann Rheum Dis. 1999:58(7):415-22

5. Nossent JC, Swaak AJ. Systemic lupus erythematosus. VII: frequency and impact of secondary Sjögren's syndrome. Lupus. 1998;7(4):231-4.

6. Gilboe IM, Kvien TK, Uhlig T, Husby G. Sicca symptoms and secondary Sjögren's syndrome in systemic lupus erythematosus: comparison with rheumatoid arthritis and correlation with disease variables. Ann Rheum Dis. 2001;60(12):1103-9.

7. Salliot C, Mouthon L, Ardizzone M, Sibilia J, Guillevin L, Gottenberg JE, Mariette X. Sjögren's syndrome is associated with and not secondary to systemic sclerosis. Rheumatology. 2007;46(2):321-6.

8. Kauppi M, Pukkala E, Isomäki H. Elevated incidence of hematologic malignancies in patients with Sjögren's syndrome compared with rheumatoid arthritis (Finland). Cancer Causes Control. 1997;8(2):201-4.
9. Martens PB, Pillemer SR, Jacobsson LT, O'Fallon WM, Matteson EL. Survivorship in a population based cohort of patients with Sjögren's syndrome 1976-1992. J Rheumatol. 1999;26(6):1296-300.

10. Turesson C, O'Fallon WM, Crowson CS, Gabriel SE, Matteson EL. Occurrence of extra-articular disease manifestations is associated with excess mortality in a community based cohort of patients with rheumatoid arthritis. J Rheumatol. 2002;29(1):62-7.

11. Sutcliffe N, Stoll T, Pyke S, Isenberg DA. Functional disability and end organ damage in patients with systemic lupus erythematosus (SLE), SLE and Sjögren's syndrome (SS), and primary SS. J Rheumatol. 1998;25(1):63-8.

12. Baldini C, Giusti L, Ciregia F, Da Valle Y, Giacomelli C, Donadio E, Sernissi F, Bazzichi L, Giannaccini G, Bombardieri S, Lucacchini A. Proteomic analysis of saliva: a unique tool to distinguish primary Sjögren's syndrome from secondary Sjögren's syndrome and other sicca syndromes. Arthritis Res Ther. 2011;13(6):R194.

13. Kyriakidis NC, Kapsogeorgou EK, Tzioufas AG. A comprehensive review of autoantibodies in primary Sjögren's syndrome: clinical phenotypes and regulatory mechanisms. J Autoimmun. 2014;51:67-74.

14. Bournia VK, Vlachoyiannopoulos PG. Subgroups of Sjögren syndrome patients according to serological profiles. J Autoimmun. 2012;39(1-2):15-26.

15. Goëb V, Salle V, Duhaut $P$, Jouen F, Smail A, Ducroix JP, Tron F, Le Loët X, Vittecoq $O$. Clinical significance of autoantibodies recognizing Sjögren's syndrome A (SSA), SSB, calpastatin and a-fodrinin primary Sjögren's syndrome. Clin Exp Immunol. 2007;148(2):281-7.

16. Lunardi C, Bason C, Navone R, Millo E, Damonte G, Corrocher R, Puccetti A. Systemic sclerosis immunoglobulin $\mathrm{G}$ autoantibodies bind the human cytomegalovirus late protein UL94 and induce apoptosis in human endothelial cells. Nat Med. 2000;6(10):1183-6.

17. Lunardi C, Bason C, Leandri M, Navone R, Lestani M, Millo E, Benatti U, Cilli M, Beri R, Corrocher R, Puccetti A. Autoantibodies to inner ear and endothelial antigens in Cogan's syndrome. Lancet. 2002;360(9337):915-21.

18. Puccetti A, Baxon C, Simeoni S, Millo E, Tinazzi E, Beri R, Peterlana D, Zanoni G, Senna G, Corrocher R, Lunardi C. In chronic idiopathic urticaria autoantibodies against FcERII/CD23 induce histamine release via eosinophil activation. Clin Exp Allergy. 2005;35(12):1599-607.

19. Frulloni L, Lunardi C, Simone R, Dolcino M, Scattolini C, Falconi M, Benini L, Vantini I, Corrocher R, Puccetti A. Identification of a novel antibody associated with autoimmune pancreatitis. N Engl J Med. 2009;361(22):2135-42.

20. Vitali C, Bombardieri S, Jonsson R, Moutsopoulos HM, Alexander EL, Carsons SE, Daniels TE, Fox PC, Fox RI, Kassan SS, Pillemer SR, Talal N, Weisman MH, European Study Group on Classification Criteria for Sjögren's Syndrome. Classification criteria for Sjögren's syndrome: a revised version of the European criteria proposed by the American-European Consensus Group. Ann Rheum Dis. 2002;61(6):554-8.

21. Aletaha D, Neogi T, Silman AJ, Funovits J, Felson DT, Bingham 3rd CO, Birnbaum NS, Burmester GR, Bykerk VP, Cohen MD, Combe B, Costenbader KH, Dougados M, Emery P, Ferraccioli G, Hazes JM, Hobbs K, Huizinga TW, Kavanaugh A, Kay J, Kvien TK, Laing T, Mease P, Ménard HA, Moreland LW, Naden RL, Pincus T, Smolen JS, Stanislawska-Biernat E, Symmons D, Tak PP, Upchurch KS, Vencovský J, Wolfe F, Hawker G. 2010 rheumatoid arthritis classification criteria: an American College of Rheumatology/European League Against Rheumatism collaborative initiative. Ann Rheum Dis. 2010;69(9):1580-8.

22. Shen L, Kapsogeorgou EK, Yu M, Suresh L, Malyavantham K, Tzioufas AG, Ambrus Jr JL. Evaluation of salivary gland protein 1 antibodies in patients with primary and secondary Sjogren's syndrome. Clin Immunol. 2014;155(1):42-6.

23. Horval AE, Li L, Xu Z, Kramer MJ, Jablons DM, Treseler PA. C-Kit is not expressed in malignant mesothelioma. Mod Pathol. 2003;16(8):818-22.

24. Wellings DA, Atherton E. Standard Fmoc protocols. Methods Enzymol. 1997;289:44-67.

25. Chen M, Lam BK, Luster AD, Zarini S, Murphy RC, Bair AM, Soberman RJ, Lee DM. Joint tissues amplify inflammation and alter their invasive behavior via leukotriene $\mathrm{B}_{4}$ in experimental inflammatory arthritis. J Immunol. 2010; 185(9):5503-11.

26. Richards A, Mutlu S, Scully C, Maddison P. Complications associated with labial salivary gland biopsy in the investigation of connective tissue disorders. Ann Rheum Dis. 1992;51(8):996-7.

27. Azumi N, Battifora $\mathrm{H}$. The distribution of vimentin and keratin in epithelial and nonepithelial neoplasms: a comprehensive immunohistochemical study on formalin- and alcohol-fixed tumors. Am J Clin Pathol. 1997;88(3):286-96.

28. Hjelmervik TO, Jonsson R, Bolstad AL. The minor salivary gland proteome in Sjögren's syndrome. Oral Dis. 2009;15(5):342-53. 
29. Bang H, Egerer K, Gauliard A, Lüthke K, Rudolph PE, Fredenhagen G, Berg W, Feist E, Burmester GR. Mutation and citrullination modifies vimentin to a novel autoantigen for rheumatoid arthritis. Arthritis Rheum. 2007;56(8):2503-11.

30. Mathsson L, Mullazehi M, Wick MC, Sjöberg O, van Vollenhoven R, Klareskog $L$, Rönnelid J. Antibodies against citrullinated vimentin in rheumatoid arthritis: higher sensitivity and extended prognostic value concerning future radiographic progression as compared with antibodies against cyclic citrullinated peptides. Arthritis Rheum. 2008;58(1):36-45.

31. Innala L, Kokkonen H, Eriksson C, Jidell E, Berglin E, Rantapää-Dahlqvist S. Antibodies against mutated citrullinated vimentin are a better predictor of disease activity at 24 months in early rheumatoid arthritis than antibodies against cyclic citrullinated peptides. J Rheumatol. 2008;35(6):1002-8.

32. Ursum J, Nielen MM, van Schaardenburg D, van der Horst AR, van de Stad RJ, Dijkmans BA, Hamann D. Antibodies to mutated citrullinated vimentin and disease activity score in early arthritis: a cohort study. Arthritis Res Ther. 2008;10(1):R12

33. Paisansinsup T, Deshmukh US, Chowdhary VR, Luthra HS, Fu SM, David CS HLA class II influences the immune response and antibody diversification to Ro60/Sjögren's syndrome-A: heightened antibody responses and epitope spreading in mice expressing HLA-DR molecules. J Immunol. 2002;168(11): 5876-84.

34. Durai M, Kim HR, Moudgil KD. The regulatory C-terminal determinants within mycobacterial heat shock protein 65 are cryptic and cross-reactive with the dominant self homologs: implications for the pathogenesis of autoimmune arthritis. J Immunol. 2004;173(1):181-8.

35. van der Woude D, Rantapää-Dahlqvist S, loan-Facsinay A, Onnekink C Schwarte CM, Verpoort KN, Drijfhout JW, Huizinga TW, Toes RE, Pruijn GJ. Epitope spreading of the anti-citrullinated protein antibody response occurs before disease onset and is associated with the disease course of early arthritis. Ann Rheum Dis. 2010;69(8):1554-61.

36. Zhao ZS, Granucci F, Yeh L, Schaffer PA, Cantor H. Molecular mimicry by herpes simplex virus-type 1: autoimmune disease after viral infection. Science. 1988:279(5355):1344-7.

\section{Submit your next manuscript to BioMed Central and we will help you at every step:}

- We accept pre-submission inquiries

- Our selector tool helps you to find the most relevant journal

- We provide round the clock customer support

- Convenient online submission

- Thorough peer review

- Inclusion in PubMed and all major indexing services

- Maximum visibility for your research

Submit your manuscript at www.biomedcentral.com/submit 